\title{
Confronting Student Prejudice with "Mario KarT" NinTENDO WiI*
}

\author{
AnNA E. KosloskI \\ Iowa State University \\ BRIDGET K. WeLCH \\ Western Illinois University
}

\begin{abstract}
This paper explores the use of "Mario Kart" Nintendo Wii as an active learning tool to teach about intergroup conflict as a cause of prejudice. Participating students were randomly placed into two "Mario Kart" Nintendo Wii tournaments. Students then competed as team members and ranked personality traits for their team (in-group) and the opposing team (out-group). Discussion of the results focused on the role of competition in creating in-group/out-group biases and how this relates to prejudice. Results from a pre-test/post-test quiz indicated that students understood these concepts more clearly after the tournaments were held. Furthermore, those who participated improved their scores more than those who did not participate in the tournaments.
\end{abstract}

*Authorship is alphabetical. Correspondence to: Anna E. Kosloski, Iowa State University, 418 East Hall, Ames, IA 50011-1070; Phone: (515) 2948108; email: kos10021@iastate.edu. Bridget K.Welch, Western Illinois University, Morgan Hall 403, Macomb, IL. 61455; Phone: (309) 298-2418; email: BK-Welch@wiu.edu.

Anna E. Kosloski is a Doctoral Candidate at Iowa State University. Her research focuses on issues surrounding women's incarceration in the United States. She has taught Introduction to Sociology, Women and Crime, and Social Psychology at Iowa State University. Contact can be directed to her at kos10021@iastate.edu. Bridget K. Welch is an Assistant Professor of Sociology at Western Illinois University. Her research areas are social psychology and race, class and gender. She regularly teaches Introduction to Sociology, Research Methods, and a variety of classes in both social inequalities and social psychology. Contact can be directed to her at bk-welch@wiu.edu. 
Acknowledgements: The authors would like to thank Dwight D. Dake for his help with the technological component of this exercise. They would also like to thank Terry L. Besser for comments on an earlier version of this paper.

\section{Introduction}

There is a growing pedagogical shift within higher education to encourage students to become engaged within the classroom environment. Rather than having student sit passively during lectures, instructors are challenging students to "formulate their own ideas, interpret data, generate conclusions from experimental evidence, and participate in other "hands-on" activities" in the classroom (Campisi and Finn 2011: 38). These active learning strategies encourage the development of critical thinking skills, information synthesis, and knowledge application (Campisi and Finn 2011; Kane 2004; Nelson Laird et. al. 2008). One pedagogical technique utilized across disciplines to facilitate active learning is the use of simulations and games.

Sociologists have been using simulations and games as an alternative approach to lecturing for decades (Dorn 1989; Dundes and Harlow 2005; Fisher 2008; Piano and Chin 2011) while largely ignoring possible video game applications because of a focus on the potential negative effects (e.g., encouraging aggression and violence) of game play (Aguilera and Mendiz 2003). Despite these negatives, video games can be influential in students' ability to develop and refine inductive logic, solve problems, and play an active role in their education (Aguilera and Alfonso 2003; Bowman 1982).

As such, we have two main goals for this study. First, we provide an example of a video game as an active learning technique. We utilized "Mario Kart" Nintendo Wii for this example because of its popularity and ease of use. This game was one of the top five video games titles globally when it was released in 2008 (ESA 2009). Additionally, Nintendo Wii games have been praised for the ease of usability and appeal to a broader audience than other gaming systems (Pearson and Bailey 2007). Second, we describe 
an active learning technique for teaching about prejudice. Many researchers in sociological pedagogy have noted that students resist both the idea that there is still prejudice in the United States and, more forcefully, the notion that they could be prejudiced (even if unconsciously). In response, many teachers have developed active learning techniques to challenge their students' false beliefs (Coghlan and Huggins 2004; Groves, Warren and Witschger 1996; Wills, Brewster and Fulkerson 2005). Our paper adds to the growing tool-kit for teaching about such issues.

\section{Prejudice and In-Group Bias}

Prejudice has two components: "a negative emotion or affective feeling toward the target group (antipathy) and a poorly founded belief about members of the target group (a stereotype)" (Quillian 2006: 300). While there are many sources of prejudice, from living in a "sick culture" to the very nature of our thought processes, this teaching technique focuses on one source-group membership.

In 1954, two groups of white, middle class, eleven yearold boys went to summer camp in Oklahoma's Robber's Cave State Park (Sherif et. al 1961). During the first week, both groups named themselves and made t-shirts and a team flag to proclaim their group identities. The two groups initially did not know of the other group. When they found out, each group begged to have a tournament against "the outsiders." The result of the competition was heightened animosity.

What explains the development of such a level of hostility that even fist fighting broke out among "normal well-adjusted individuals" who are similar in terms of race, class, gender, and age (Sherif et. al 1961: 426)? While Sherif and colleagues would argue that intergroup conflict is based on competition for scarce resources, Tajfel and his associates (Tajfel and Turner 1979) would argue that this competition would aid the development of group cohesion, but that it is group identification that is central to fomenting conflict.

In one of the earliest tests of this idea, Tajfel (1970) ${ }^{1}$ had

${ }^{1}$ The review here is of the classic readings on social identity theory that were 
boys estimate the number of dots on a series of slides. Based on random assignment, Tajfel then told each boy that he was either an "over-estimator" (on average guessed that there were more dots than actually existed) or "under-estimator" (on average guessed that there were fewer dots than actually existed). Each boy then was asked to distribute money to the others in the study. The only information available to the participants was whether the person was an over- or under-estimator. He found that group members favored members of their in-group (i.e., over-estimators favored other over-estimators) and gave less to the out-group (i.e., overestimators allocated less money to under-estimators).

Simply defining oneself as a member of a group is enough to create in-group bias and prejudice against the out-group. If simple assignment to a group is enough to make a student believe that her group is better along many dimensions (and, thus, the out-group is worse), the corollary to what occurs when she is placed in a group based on differences that are socially constructed as meaningful (e.g. race, class, gender, sexuality) becomes harder for her to deny. To make this point during the exercise, in-group/out-group bias was compared across two types of groups - one that was given some basis for membership and one that was given no basis at all.

\section{Methods}

Participants were undergraduate students enrolled in a social psychology course at a large public university. To follow ethical guidelines, students were given the option to not participate in any part of the study (the experiment itself and access to their quiz scores). Nineteen students (out of 30) choose to participate in the activity and another seven agreed to release their scores. The study consisted of three components: (1) the pre-and posttest of information retention; (2) the active learning technique or competition; and (3) assessment of in-group bias.

Information Retention. Students were assigned to read the Tajfel (1970) article discussed above. Students were also encouraged (though not assigned) to read a discussion of Sherif's assigned in the course that tested this teaching technique. Social identity theory is still very prominent in sociological social psychology (see Harrod, Welch and Kushkowski 2009). 
"Robbers Cave" experiment (Sherif et. al 1961). They then attended a lecture about intergroup conflict and social identity theory. All students then took a five question short answer quiz scored by the instructor. Each question was given a value of ten points (for a total of fifty). This score served as the pre-test of information retention. The post-test of information retention occurred after the competition was held. The day this information was collected, the instructor recapped the earlier lecture and discussed the results from the competition. The students then retook the intergroup conflict quiz, which was scored in the same way as the first quiz.

Competition. The active learning technique consisted of an experiment assigning students to teams in a Mario Kart Nintendo Wii tournament with two conditions: (1) Participants were given a rationale for their group assignment, and (2) Participants were told that they were randomly assigned to a group. Several weeks after the initial quiz and discussion of Tajfel (1970), students were asked to complete the dot estimation task. When students arrived on the day set aside for the tournament (nineteen students), they were randomly assigned to a condition. Those assigned to condition one were told that they were either under- (five students) or overestimators (five students). ${ }^{2}$ Those assigned to condition two were told that their responses did not clearly categorize them as underor over-estimators. Instead, they were told that they were simply randomly assigned to Team A (four students) or Team B (four students).

The four groups were then entered into two Mario Kart Nintendo Wii tournaments held in separate rooms (over-estimators vs. under-estimators and Team A vs. Team B). Before beginning the two tournaments, every student had the opportunity to practice with the Nintendo Wii remotes. Practice lasted for approximately twenty minutes. The tournament consisted of each team member playing one race against a member of the other team. A game took about half an hour to complete.

In-group Bias. After the completion of each tournament, all students filled out a questionnaire assessing the same personality

${ }^{2}$ During random assignment, one student decided not to participate in the tournament but simply wanted to watch. 
traits for member of their own team (the in-group) and members of the competition (the out-group). Adapted by Foels (2006), the questionnaire asked participants to rank their own group and the other group on each trait (one "not at all" to seven "very much"). The 24 traits were all positive (e.g. smart, happy, and truthful). An estimate of bias was created by totaling how each individual ranked his own team on the 24 traits and subtracting the total of his ranking of traits for the other team.

\section{Results}

There are two sets of results to report - the results of the tournament and the effect of participation on information retention. Each will be discussed below.

\section{The Tournament}

Utilizing a paired samples t-test, we compared self-evaluation (how highly students ranked their own team) to other-evaluation (how highly students ranked the competing team). Participants ranked their own team, regardless of condition, significantly higher than they did the competing team $(\mathrm{t}=6.3$, df $=17, \mathrm{p}<$ 0.01 ). We also assessed whether individuals who were told they were randomly assigned to their group would experience less bias than those who were provided with a rationale. Utilizing an independent samples t-test, we found there was no significance difference $(\mathrm{t}=.579, \mathrm{df}=16, \mathrm{p}=.571)$, indicating that providing a rationale did not increase bias. These findings were used to lead a discussion about the development of prejudice.

\section{Efficacy of Learning Technique}

Eighteen students participated in the activity and another seven signed informed consent to allow the use of their quiz scores for comparison. For pre-test and post-task comparisons, we only compared those who were present for both tests $(n=19)$. This resulted in 13 who participated in the tournaments and 6 who did not. For these individuals, a mean score of 21.57 (s.d. $=12.47$ ) was obtained on the first test, and a mean score of 35 (s.d. $=10.80)$ was obtained on the second test. 
All students averaged 13.42 points in improvement (s.d. $=8.98$ ) from the pre-test to the post-test. Participation in the competition increased this improvement. Those who were active participants improved their scores by an average of 16.15 points $($ s.d. $=8.9)$ while those who did not play improved by an average of 7.5 points $($ s.d. $=6.12$ ). Students who participated in the tournament improved on average by 8.65 points more than those students who did not. An independent samples t-test indicated this difference was significant.

Finally, it is possible that students who attended the optional class were stronger students in general, and it is this selection bias that accounts for the difference in scores and not participation in the activity. To test this, we ran an independent samples t-test on the scores from the first quiz comparing those who participated and those who did not. With no significant difference between the groups $(\mathrm{t}=.02$, df $=17, \mathrm{p}=0.98)$, we can conclude that it is participation that drove improved test results.

\section{Discussion}

This study had two primary goals. First, we sought to provide an example of how video games could be utilized in the classroom. Second, we wanted to provide a teaching technique that would help students retain information and move beyond their resistance to acknowledging prejudice. To do this, we provided students with information about social identity theory, which, at its core, is a theory about how simply belonging to a group is enough to create prejudice against an out-group. To test this, we assigned students to groups either based on a slight rationale (under- or overestimators) or based on no rationale at all (randomly assigned). Two Mario Kart Nintendo Wii tournaments were then played and in-group bias was estimated. Findings revealed in-group bias regardless of reason for group membership.

First, bringing Nintendo Wii into the classroom for the purpose of this active learning exercise allowed us to explore a new medium for instruction that has been relatively ignored within higher education. It also encouraged students to think sociologically while engaging in an activity from popular culture, a combination 
they thoroughly enjoyed. As one student remarked, "I had to come to class today. I don't know when else I'll be allowed to play Wii on campus." Many students who did not come to the tournament later voiced regret for missing the opportunity. ${ }^{3}$ The excitement was evident during the tournament with students becoming very vocal, cheering and good naturedly jeering during each race.

Second, the benefit of this technique is clear in terms of information retention. Students who were exposed to the material in a traditional manner - through lecture, discussion, and reading alone-did not improve as much as those who participated in the tournaments. Further, discussion of the tournaments clearly revealed that students came to a fuller understanding of prejudice and its continued existence in American society. Students expressed amazement that simply being assigned to a category membership could result in prejudice against out-group members. The implication of how this would work with socially meaningful categorizations (e.g. race and gender) was clear to students. Overall, we found the Nintendo Wii experiment to be a useful and a contemporary way to illustrate in-group conflict and foster discussion about prejudice.

\section{References}

Aguilera, Miguel and Alfonso Mendiz. 2003. "Video Games and Education." ACM Computers in Entertainment 1 (6): 1-14.

Bowman, R.F. 1982. "A Pac-Man Theory of Motivation. Tactical Implications for Classroom Instruction." Educational Technology 22(9): 14-17.

Campisi, Jay and Kevin E. Finn. 2011. "Does Active Learning Improve Students' Knowledge of and Attitudes Toward Research Methods?" Journal of College Science Teaching 40 (4): 38-45.

Dorn, Dean S. 1989. "Simulation Games: One More Tool on the Pedagogical Shelf." Teaching Sociology 17 (1): 1-18.

Dundes, Lauren and Roxanna Harlow. 2005. "Illustrating the Nature of Social Inequality with the Simulation Star Power." Teaching Sociology 33(1): 32-43.

ESA. 2009. 2009 Sales, Demographic and Usage Data, Essential Facts

\footnotetext{
${ }^{3}$ In fact, several students reported not coming because of a very large snow storm that occurred the same day as the tournament, not due to lack of desire to participate.
} 
about the Computer and Video Game Industry. Washington DC: Entertainment Software Association.

Fisher, Edith M. 2008. "USA Stratified Monopoly: A Simulation Game about Social Class Stratification." Teaching Sociology 36(3): 272282.

Foels, Rob. 2006. "In-group Favoritism and Social Self-Esteem in Minimal Groups: Changing a Social Categorization into a Social Identity." Current Research in Social Psychology 12: 38-53.

Harrod, Wendy J., Bridget K. Welch, and Jeff Kushkowski. 2009. "Thirty-one Years of Group Research in Social Psychology Quarterly (1975-2005): Topical, Methodological, and Bibliometric Analysis." Current Research in Social Psychology 14(6): 75-103.

Kane, Liam. 2004. "Educators, Learners, and Active Learning." International Journal of Lifelong Education 23(3): 275-286.

Nelson Laird, Thomas F., Rick Shoup, George D. Kuh, and Michael J. Schwarz. 2008. "The Effects of Discipline on Deep Approaches to Student Learning and College Outcomes." Research in Higher Education 49: 469-494.

Paino, Maria and Jeffrey Chin. 2011. "MONOPOLY and Critical Theory: Gaming in a Classroom on the Sociology of Deviance." Simulation and Gaming. Retrieved April 28, 2011. (http://sag.sagepub.com/ content/early/2011/03/01/1046878110391022.full.pdf+html).

Pearson, Elaine and Chris Bailey. 2007. "Evaluating the Potential of the Nintendo Wii to Support Disabled Students in Education." Proceedings Ascilite, Singapore, Presentation.

Quillian, Lincoln. 2006. "New Approaches to Understanding Racial Prejudice and Discrimination." Annual Review of Sociology 32: 299-328.

Sherif, Muzafer, O.H. Harvey, B. Jack White, William R. Hood and Carolyn W. Sherif. 1961.

Intergroup Conflict and Cooperation. The Robbers Cave Experiment. Norman, OK: Institution of Group Relations.

Tajfel, Henri. 1970. "Experiments in Intergroup Discrimination." Scientific American 223: 96-102.

Tajfel, Henri and John C. Turner. 1979. "An Integrative Theory of Intergroup Conflict." Pp. 33- 47 in The Social Psychology of Intergroup Relations, edited by W.G. Austin and S. Worchel. Monterey: Brooks-Cole. 
